\title{
PLANEJAMENTO E IMPLEMENTAÇÃO DE CURSO ONLINE COMO ATIVIDADE DE ESTÁGIO CURRICULAR NA ÁREA DE INGLÊS
}

\section{PLANNING AND IMPLEMENTING AN ONLINE COURSE AS A TEACHING PRACTICUM ACTIVITY IN ENGLISH LANGUAGE TEACHING $^{1}$}

Telma Gimenez

Universidade Estadual de Londrina

Samantha Gonçalves Mancini Ramos

Universidade Estadual de Londrina

\section{Resumo}

Embora tenha havido crescimento considerável no uso de Tecnologias de Informação e Comunicação (TIC) no ensino a distância no Brasil na última década, a formação de professores de línguas estrangeiras para esse contexto ainda se dá de modo tímido. Neste artigo relatamos a experiência de realização de estágio na Prática de Ensino de Inglês em um curso de Letras, na qual os professores em formação se encarregaram de todas as etapas de realização de um curso de extensão oferecido na plataforma Moodle. Orientado por abordagem reflexiva e colabo-

\begin{tabular}{|l|l|l|l|l|}
\hline Ilha do Desterro & Florianópolis & n 66 & p. 101- 131 & jan/jun 2014 \\
\hline
\end{tabular}


rativa, o processo formativo incluiu a redação de um artigo acadêmico relativo à experiência. Os artigos dos cinco estagiários que realizaram a prática de ensino nessa modalidade em 2013 foram analisados, buscando-se verificar suas representações por meio das apropriações da literatura bem como das considerações sobre a prática na construção de conhecimento sobre ensino a distância. $\mathrm{O}$ contato com a literatura parece ter servido para fortalecer a adesão à proposta do estágio e a experiência vivida apontou para aspectos que poderiam ser melhorados em futuras ofertas do mesmo curso. Os resultados sugerem que oportunidades como as relatadas poderiam contribuir para construção de conhecimentos teórico-práticos sobre ensino a distância.

Palavras-chave: ensino a distância, formação de professores, língua inglesa.

\section{Abstract}

Although there has been considerable growth in the use of Information and Communication Technologies (ICT) in distance education in Brazil in the last decade, the education of foreign language teachers in this context seems to remain scarce. We report the experience of an English language teaching practicum in a 'Letras' course in which student-teachers were responsible for all stages of design and implementation of an extracurricular course offered on the Moodle platform. Guided by a reflective and collaborative approach, the professional preparation process included the writing of an academic article on the experience. The papers written by the five student teachers who did their practicum by means of this mode in 2013 were analyzed. The purpose was to verify the appropriation of literature as well as practical considerations in building knowledge about distance learning. The contact with the literature seems to have served to strengthen adherence to the supervisor's proposal and the lived experience pointed to aspects that could be improved in future offers of the same course. The results suggest that opportunities such as those reported could contribute to the construction of theoretical and practical knowledge about distance learning.

Keywords: distance learning, teacher education, English language. 


\section{Introdução}

Os recentes avanços tecnológicos no campo da informação e comunicação são inegáveis. Ferramentas como a internet e aplicativos para os mais diversos suportes permitem superar as distâncias e aproximar pessoas que se conectam a uma imensa rede. Ainda que o acesso a essas tecnologias se dê de modo desigual, parece igualmente irrefutável que, mesmo em situações de privação, essas tecnologias exercem um papel relevante na vida cotidiana. A linguagem exerce papel fundamental nesse processo, pois faz parte dos processos semióticos de construção de sentidos em sociedades cada vez mais dependentes dessas tecnologias. Professores de línguas têm, deste modo, papel relevante na educação de cidadãos conscientes desse papel assim como no de avaliar as consequências de paradigmas educacionais atravessados por essas tecnologias. Por esse motivo, consideramos necessário possibilitar que, durante a formação inicial, estagiários experimentem, como alunos, como professores e como tutores, aprendizagens em ambientes virtuais de aprendizagem (doravante AVA).

No campo de ensino de línguas estrangeiras, autores como Paiva (2013) e Leffa (2006) têm salientado a importância de familiarização de futuros professores com os artefatos digitais. Peachey (www.nikpeachey.blogspot.com) apresenta inúmeras referências de sites gratuitos para produção de atividades complementares à educação presencial, ou mesmo, para oferta de cursos online. Assim, tem sido cada vez mais enfatizado que as tecnologias digitais devem se colocar a serviço dos objetivos educacionais, inclusive como forma de articular as vivências na escola e fora dela (El Kadri; Gamero; Gimenez, 2012).

No caso da experiência aqui relatada, buscou-se incluir nos processos formativos profissionais oportunidades de experimentação 
com essas tecnologias, de modo a situá-las no contexto educacional em geral. Esse tipo de educação é uma realidade ainda incipiente no contexto brasileiro, embora haja iniciativas por parte da Universidade Aberta do Brasil para realização de cursos de formação continuada de professores. ${ }^{2}$ Registra-se, portanto, que a experiência aqui relatada é pioneira na instituição e, provavelmente, em outras universidades brasileiras ${ }^{3}$. Há muitos estudos sobre uso de tecnologias digitais e gêneros virtuais na formação de professores de língua inglesa, mas nenhum que trate da inclusão do contexto online como campo de estágio, e não apenas como ferramenta de realização da supervisão no estágio (e.g. Marcelo de Jesus 2010; Soto; Gregolin; Rozenfeld 2012; Ramos 2012; Paiva 2012).

Neste artigo, apresentamosas ações empreendidas para realização de estágio supervisionado de Língua Inglesa em AVA. Primeiramente apresentaremos o contexto no qual o curso foi elaborado e implementado ao explorar as diretrizes institucionais para realização do estágio e as ações de transposição ao ambiente virtual. Comentaremos sobre o processo de elaboração das atividades pelos estagiários $^{4}$ e orientadora. Em seguida, mencionaremos as diferentes fases de condução do curso "A short history of the English language", ofertado totalmente na modalidade virtual, como evento de extensão.

Após breve introdução do contexto de elaboração e implementação do curso, seguiremos com a análise dos trabalhos acadêmicos finais (papers) produzidos pelos 5 discentes que realizaram seus estágios em AVA. Objetivamos investigar as representações desses estagiários sobre ensino virtual conforme verbalizadas nas versões finais dos artigos submetidos. Ao buscarmos estas representações focaremos em dois momentos da referida produção: 1) a revisão de literatura e 2) a análise dos dados e conclusões finais. 


\section{Estágio Curricular em AVA: do planejamento à implementação}

$\mathrm{Na}$ instituição onde atuamos, a formação de professores de língua inglesa, em nível de graduação em licenciatura única, tradicionalmente toma a escola pública como local privilegiado para realização de estágio. Esta decisão decorre do entendimento de que uma universidade pública, como é o caso, tem responsabilidade pela educação crítica de futuros professores que poderão atuar no contexto público (e.g. Gimenez; Góes Monteiro, 2011; Mateus; El Kadri; Silva, 2013). Consideramos, portanto, que os graduandos precisam conhecer e engajar-se com as questões pertinentes ao ensino de língua inglesa nas escolas regulares de ensino fundamental e médio.

De acordo com o projeto político-pedagógico do curso de Letras-Inglês, sua finalidade é "formar professores para atuar nas áreas de Língua Inglesa e Literaturas de Língua Inglesa, no ensino fundamental e médio, capazes de aliarem a formação teórica com a prática profissional, de forma crítica e reflexiva", o que não exclui os contextos privados e não presenciais.

O estágio obrigatório de 400 horas é realizado nos $3^{\circ}$ e $4^{\circ}$ anos, em uma grade curricular de 4 anos. Os campos de estágio incluem observações em diferentes contextos e pelo menos $50 \%$ de regência (em alguns casos, compartilhada entre formador, professor colaborador na escola e estagiários) em escolas públicas. Na última década, diferentes configurações de estágio foram introduzidas em decorrência de transformações engendradas por aportes teórico-metodológicos no campo dos estudos socioculturais, tomados como referência nas várias atividades de pesquisa/ensino/extensão desenvolvidas pelo grupo de formadores nessa instituição (El Kadri, 2014).

Mediante reunião de planejamento, no início do ano, cada supervisor define seu plano de trabalho e as escolas onde irá atuar, bem como o 
número de alunos que irá orientar. No ano de 2013, um novo contexto de estágio foi selecionado - um curso online - a ser ofertado na plataforma Moodle via Pró-Reitoria de Extensão da universidade. Cinco alunos do $4^{\circ}$ ano, que já tinham realizado estágio em escolas públicas no ano anterior, escolheram esta modalidade de estágio na disciplina 6EST 114 - Estágio em Língua Inglesa II, por esta atender aos seus anseios de vivenciar ensino-aprendizagem em AVA. O objetivo foi o de complementar a formação profissional de futuros professores de inglês com atividades práticas, na modalidade a distância, de modo a possibilitar novas experiências profissionais (cf. Torres \& Siqueira, 2012).

Os estagiários cumprem a carga horária de 200 horas anuais por meio de encontros coletivos ${ }^{5}$, orientações individuais ${ }^{6}$, trabalhos acadêmicos resultante de pesquisa ${ }^{7}$ e vivência no contexto escolar ${ }^{8}$. De fato, a disciplina "Estágio em Língua Inglesa II" apresenta a seguinte ementa: Observação de contextos educacionais. Uso de tecnologia no ensino. Análise e produção de material didático. Análise de práticas de avaliação. Regência em diferentes contextos. Pesquisa-ação, e tem os seguintes objetivos:

- Vivenciar, na qualidade de professores em formação, situações de ensino-aprendizagem em sistemas de educação;

- Desenvolver capacidade autorreflexiva na formação profissional;

- Conhecer as potencialidades do campo profissional de professores de inglês e as oportunidades de formação continuada;

- Transformar a sala de aula, a escola e as situações de Prática de Ensino de Inglês em lugar privilegiado de investigação/teorização sobre fenômenos ligados ao ensino-aprendizagem. 
O estágio com foco em tecnologias apresentou várias características inovadoras em relação ao que costumeiramente se faz na instituição. Uma delas foi a de que as interações presenciais de orientação, ou seja, as orientações coletivas, das quais participaram todos os estagiários sob a coordenação da mesma supervisora, foram complementadas por comunicação em ambiente virtual. Isso permitiu potencializar o uso de ferramentas digitais, tanto para a tarefa de ensinar quanto a de aprender, aumentando o contato com a supervisora e também possibilitando que a colaboração entre os pares fosse dinâmica. Assim, as atividades de orientação de estágio foram realizadas em ambiente presencial e não presencial, conforme detalhado a seguir.

Outra característica foi a de que o curso ofertado pelos estagiários tratou de um tema pouco abordado: a história da língua inglesa, ministrado totalmente em inglês, o que exigiu que os futuros professores aprendessem sobre o assunto ao mesmo tempo em que planejavam a organização das tarefas em AVA. As ferramentas, portanto, foram utilizadas a partir do interesse em conhecer mais sobre o assunto a ser abordado; isto é, foram mobilizados os recursos necessários para realização da tarefa que era a de organizar módulos para a plataforma Moodle. Essas características citadas possibilitaram a esses alunos desempenhar o papel não mais de estagiários, mas sim de professores corresponsáveis pelo curso, pois como tal, tiveram de conhecer mais sobre o assunto a ser ensinado.

Sobre o processo de elaboração/planejamento do curso, no início de 2012, logo após os primeiros contatos entre supervisor e estudantes, optou-se por criar um grupo na plataforma Edmodo, para facilitar a comunicação. Embora o Moodle pudesse igualmente servir a esse propósito, o objetivo era propiciar contato com o maior número possível de plataformas diferenciadas. Edmodo é gratuita, 
permitindo acesso via cadastro, tanto como professor quanto como aluno. Ao se cadastrar, o professor pode criar grupos. Nesse caso, foi criado o grupo "Estágio $4^{\circ}$ Ano". Todos os 5 alunos foram convidados a participar e a se inscrever no site.

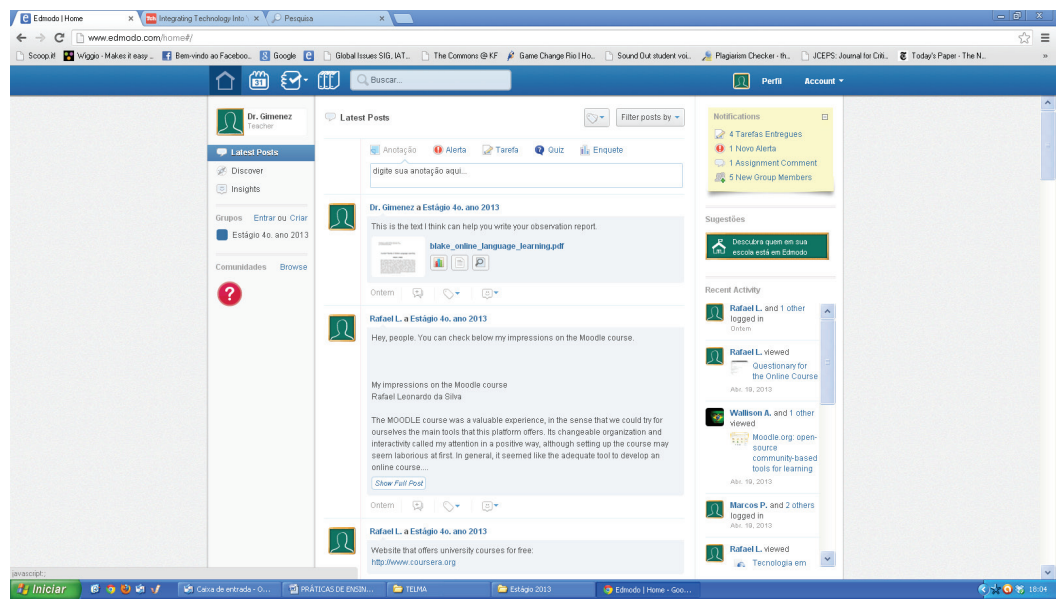

Fig 1: Página do grupo “Estágio $4^{\circ}$. Ano, na Plataforma Edmodo

Edmodo permite o registro de frequência do aluno, as tarefas feitas, e a sua nota, conforme avaliação do professor. No canto superior direito pode-se ver o número de tarefas entregues, comentários sobre tarefas, e alertas (quando se quer avisar automaticamente a respeito de um evento ou tarefa). Podem ser incluidos links, textos, "quizzes" e enquetes. Trata-se de uma plataforma simplificada, que tem como foco o controle de atividades realizadas por alunos e compartilhamento de textos e demais recursos. Entretanto, em virtude da impossibilidade de escrita colaborativa, em junho, migramos para a plataforma wiggio, tendo em vista a necessidade de feedback constante das produções dos estagiários. 
Na plataforma Wiggio, os estagiários puderam também postar links úteis, vídeos, textos e produzir, em conjunto, os textos que poderiam subsidiar o curso, cuja sigla ficou SHEL para abreviar "A short history of the English language”. Em relação à plataforma Edmodo, esta permitiu que as versões revisadas do material didático elaborado especialmente para o SHEL fossem submetidas à análise do grupo. A introdução dessas ferramentas para condução da supervisão de estágio provocou um deslocamento do papel da supervisora, pois todos os cinco alunos se sentiram responsáveis por oferecer sugestões, dar feedback e propor novos encaminhamentos.

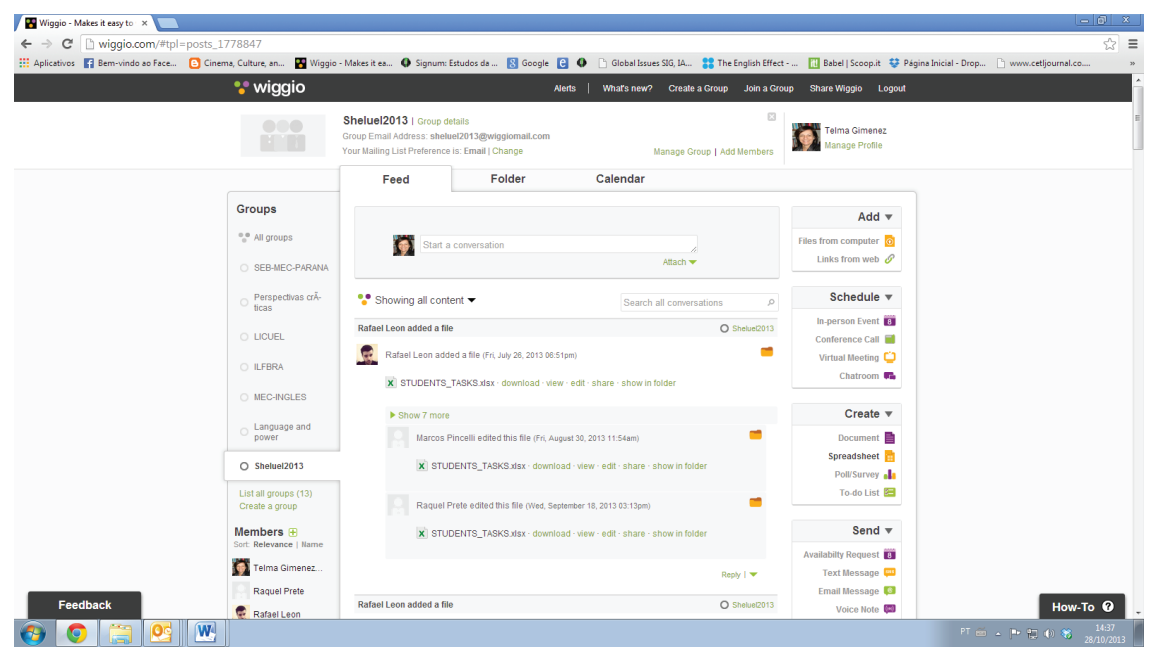

Fig. 2: Página do grupo SHELUEL na plataforma Wiggio

Esses dois ambientes de aprendizagem e suas ferramentas foram de extrema valia para a comunicação entre a supervisora e os estagiários no tempo intermediário dos encontros presenciais semanais, além de servirem como experiência de interação em AVA. Portanto, uma primeira oportunidade de aprendizagem foi a vivência nesses ambien- 
tes, gerando reflexões sobre a ferramenta e seu uso, comparando-os com a modalidade presencial com a qual estavam acostumados.

Além dessa vivência, para o cumprimento das atividades de observação, os estagiários foram orientados a fazer parte de um curso de uma língua estrangeira que desconhecessem, na plataforma LiveMocha (www.livemocha.com) ou similar. Ao final, durante o primeiro bimestre, produziram um relatório buscando tecer comparações entre essa experiência como alunos e os recursos oferecidos para aprendizagem em AVA. O objetivo dessa tarefa era possibilitar a apreciação dos desafios postos a aprendizes nesse ambiente, bem como comparar o ensino presencial praticado no ano anterior em contexto de escola pública de ensino fundamental e médio. As comparações constantes entre o presencial e o virtual foram uma importante etapa na transição para o ambiente virtual, já que este consistia na novidade.

Ainda durante o planejamento do curso para o estágio supervisionado os estagiários elaboraram um questionário, por meio do site www.surveymonkey.com, no qual potenciais alunos (estudantes de Letras-Inglês do terceiro ano) puderam indicar seus interesses.

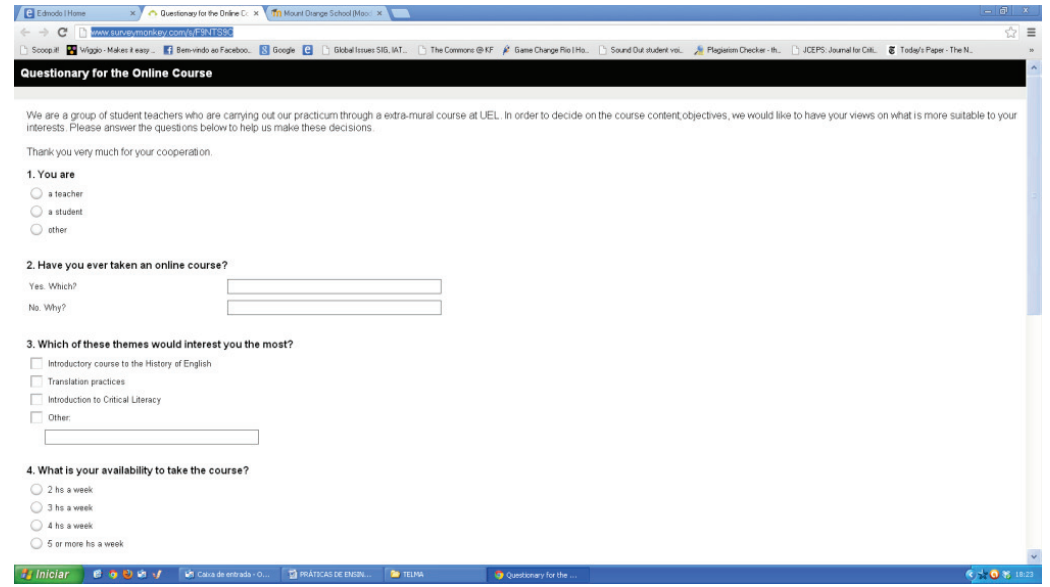

Fig. 3: questionário de sondagem de interesses no surveymonkey 
O tema da história da língua inglesa foi o favorito e tornou-se, então, o foco do curso. Tendo em vista que este não era um assunto familiar aos estagiários, pois não o tinham visto na graduação, um segundo desafio se impôs: o de aprender sobre a história da língua inglesa. Foram intensas as trocas de sites interessantes, fontes relevantes e sugestões sobre sua recontextualização pedagógica, tanto nas sessões de orientação coletiva quanto no ambiente virtual. Ao final, decidimos pela divisão em 5 módulos, um para cada estagiário, e organizados cronologicamente, como segue: Old English, Middle English, Early Modern English, Modern English e World English.

Ao mesmo tempo, os estagiários realizaram oficina, oferecida pelo Núcleo de Educação a Distância da universidade, sobre a plataforma Moodle, na qual o curso seria disponibilizado. Nessa oficina de 4 horas aprenderam sobre a plataforma e seus recursos; nas discussões presenciais tratamos de ler e discutir textos relativos ao planejamento e tutoria em AVA (e.g. Queiroz; Mustaro 2003 e Perry; Pilati 2011).

Orientamo-nos pela proposta de compartilhamento de todas as atividades; assim, as trocas entre os próprios estagiários eram frequentes, resultando na finalização do material do curso e sua inserção na plataforma no início de junho de 2013. Durante o tempo de preparação, as trocas em sessões presenciais e na plataforma Wiggio tiveram como foco a recontextualização pedagógica, uma vez que não seria o caso de simplesmente fazer, no ambiente virtual, aquilo que se faria no presencial. Para isso foram discutidos textos sobre hipertextos e características de cursos online. Para cada módulo foram planejadas três tarefas, prevendo interatividade em fóruns.

Iniciou-se, então, a divulgação do curso de extensão, cuja inscrição era gratuita e limitada a 75 participantes. A elaboração do material promocional também foi feita de forma colaborativa. Foi criado 
112 Telma Gimenez and Samantha G. M. Ramos, Planejamento...

um e-mail específico para esclarecimento de dúvidas e os graduandos se revezavam a cada semana para responder às mensagens.

Durante a implementação do curso (que teve início em 1 de julho de 2013), um novo módulo era disponibilizado quinzenalmente aos participantes. $\mathrm{O}$ estagiário responsável pelo módulo realizava a tutoria, auxiliado pelos demais colegas, quando necessário. Após dois meses e meio, o curso foi concluído por 14 participantes ${ }^{9}$. Dos 75 inscritos, apenas 47 efetivamente realizaram a primeira tarefa do primeiro módulo e, por este motivo, consideramos que a taxa de evasão esteve dentro dos parâmetros de educação totalmente a distância. Pouca familiaridade com o ambiente, bem como alguns problemas técnicos facilitaram a desistência.

De fato, as limitações do ensino-aprendizagem em AVA foram tratadas nas sessões de orientação, pois a experiência era nova para todos os envolvidos. Identificamos possibilidades de melhoria nas tarefas envolvendo interações em fóruns, dosagem de conteúdos, e questões de proficiência na língua ${ }^{10}$.

As questões emergentes da execução do curso foram objeto das reflexões realizadas pelos futuros professores em formato de texto acadêmico. A realização de pesquisa e redação de texto em forma de artigo (também conhecido como paper) foram implantadas na instituição há mais de duas décadas (Gimenez, 1998), como componente importante de uma formação reflexiva e ali têm norteado a formação inicial de professores de língua inglesa (Gimenez, 2004).

A seguir, exploraremos os 5 trabalhos produzidos a partir da experiência de estágio em AVA aqui relatada. Como mencionado anteriormente, exploraremos as representações dos estagiários verbalizadas em seus trabalhos acadêmicos em dois momentos distintos: 1) na revisão de literatura na qual evidenciaremos a apropriação da literatura sobre educação a distância e TIC por parte dos discentes 
e 2) na análise dos dados e nas conclusões finais nas quais a própria vivência como planejador, professor conteudista e tutor do curso oferecido começam a emergir. Partimos do pressuposto de que, ao tematizarem determinados ângulos da experiência, os professores em formação sinalizariam para os aspectos salientes da prática de ensino centrada na educação a distância.

\section{Experiência de formação profissional em AVA: foco nas repre- sentações discentes}

A orientação teórico-metodológica adotada durante o processo formativo na Prática de Ensino aqui relatado seguiu os pressupostos de uma formação reflexiva (Gimenez 2004; Zeichner 1993), com enfoque para o engajamento na prática, acompanhado de leituras e discussões de aspectos teóricos. Desse modo, ao mesmo tempo que tinham tarefas específicas a cumprir, os professores em formação buscavam os recursos necessários (inclusive a partir de leituras) para realizá-las.

Os textos produzidos individualmente pelos cinco estagiários (papers), em língua inglesa, são o foco deste artigo e foram analisados indutivamente, a partir da identificação temática; isto é, foram lidos pelas duas autoras, de modo independente, e posteriormente esses temas foram unificados, tendo em vista as seções apresentadas nos papers.

As reflexões sobre o estágio tiveram como foco diferentes aspectos do curso online oferecido. O primeiro deles ${ }^{11}$ (TA1) alertou sobre a lacuna existente nos cursos de formação de professores de línguas estrangeiras no que tange ao uso das tecnologias digitais. De fato, o objetivo do trabalho foi identificar as percepções dos futuros professores sobre sua formação inicial e a utilização de tecnologias digitais. 
114 Telma Gimenez and Samantha G. M. Ramos, Planejamento...

O segundo trabalho ${ }^{12}$ (TA2) concentrou-se nas percepções de alunos professores ao desempenharem o papel de tutores online durante a implementação do curso SHEL no ambiente moodle, evidenciando as problemáticas envolvidas em suas intervenções. Por sua vez,o terceiro trabalho ${ }^{13}$ (TA3) sinalizou para a introdução de gêneros digitais e de ferramentas tecnológicas na educação inicial como meio de complementar o processo de formação que, até então, era pautado em ambiente presencial e nas interações face a face. O quarto trabalho $^{14}$ (TA4) evidenciou o crescimento de pesquisas realizadas sobre a aprendizagem em ambientes virtuais e as percepções dos alunos participantes sobre o SHEL ao analisar suas interações nos fóruns de discussão. Por fim, o quinto trabalho ${ }^{15}$ (TA5) avaliou as atividades produzidas para o SHEL a partir de uma lista de checagem.

Observa-se que cada um dos estagiários abordou um aspecto da vivência na prática de ensino, embora houvesse possibilidade de temáticas similares. Essa diversidade permitiu a constituição de um mosaico de experiências, com enfoques para a tutoria (TA2 e TA4) ou para o desenho do curso (TA3 e TA5). Na fase de definição de tema para estudo foi sugerido aos estagiários que selecionassem aqueles sobre os quais teriam mais curiosidade em explorar. Essa definição ocorreu de modo concomitante à implementação do curso online embora sua redação final tenha ocorrido após sua conclusão.

\section{Apropriação de concepções sobre TIC e educação na revisão de literatura}

A redação do texto em formato de artigo (paper) requereu a apresentação de revisão de literatura. Ao fazê-la os estagiários destacaram alguns aspectos/pressupostos importantes que permeiam as novas tecnologias educacionais e que foram por eles adotados por 
meio de citações diretas e indiretas conforme podemos perceber nas seguintes afirmações:

1. A facilidade de acesso aos ambientes digitais tem promovido mudanças na esfera educacional e exigido novas competências dos (futuros) professores que devem saber utilizar as novas TIC de forma eficaz. Por sua vez, o professor formador é apontado como agente de mudança no contexto educacional e como responsável pela utilização de ferramentas que contemplem as expectativas da sociedade. Entretanto, na realidade, o formador tem apenas um conhecimento parcial/reduzido neste setor e sua contribuição ainda é limitada pelas constantes mudanças tecnológicas (TA1),

2. A Educação a Distância na forma de aprendizagem eletrônica ou aprendizagem online é um meio educacional no qual professores e alunos estão fisicamente separados e as interações ocorrem através do uso da tecnologia (TA3). Diversas modalidades de ensino estão disponíveis aos professores e aprendizes dispostos a incorporar as TIC em seus processos de ensino e aprendizagem, entre elas: Computer Assisted Learning, Web-based Learning, Online Learning, Distance Learning, E-Learning, Tandem Learning, MOOCs - Massive Open Online Courses e Mobile Learning (TA1),

3. Políticas educacionais estão sendo estruturadas para dar conta da demanda de integração das TIC na educação, porém essas propostas não têm reflexo imediato nas práticas educativas, o que pode ser explicado pelo perfil de nossos educadores que são profissionais que não tiveram treinamento em tecnologia em sua formação inicial (TA1). As Diretrizes Curriculares da Educação Bá- 
sica de Língua Estrangeira do Estado do Paraná (PARANÁ, 2008) encorajam o uso das TIC nas salas de aula, levando à crença de que os recursos já estão disponíveis e que os professores seriam os responsáveis em utilizá-los (TA1). Ainda considerando as políticas educacionais, o Decreto federal $n^{\circ} 5.622 / 05$, permite que as universidades ofereçam até $20 \%$ de seus cursos utilizando plataformas online, o que pode incentivar a utilização das TIC no processo de formação inicial. Além disso, conforme dados do INEP 2011, cursos de graduação ofertados em formato híbrido (presencial e não presencial) ou totalmente a distância já somam 15\% dos alunos matriculados em cursos de graduação no Brasil (TA4)

4. Sobre o currículo da formação inical de professores, seria desejável basear-se nas seguintes compreensões: a tecnologia deve permear todo o currículo e não apenas ser ofertado como um momento específico; a tecnologia deve ser utilizada no processo de se aprender sobre ela; a aprendizagem tecnológica deve ser conectada a experiências em situações reais, deve-se considerar as limitações de recursos tecnológicos da escola e acompanhamento dos avanços tecnológicos e, por fim, deve-se primar pela combinação entre o conhecimento técnico e pedagógico ao utilizar as tecnologias educacionais. Para além do currículo, um processo de formação inicial de professores que queira contemplar as novas tecnologias de forma significativa deve ser realizado em um ambiente de prática de ensino rico em recursos tecnológicos (TA1),

5. A Educação a Distância, em sua proposta de aprendizagem mediada por computadores, traz ao cenário educacional novos participantes: o professor - aquele que prepara o material organizando instruções, referências e atividades, o tutor - aquele que 
medeia as interações em ambientes virtuais de aprendizagem e o estudante de curso online (TA2). Nesses novos ambientes de aprendizagem, os alunos devem aprender não apenas o conteúdo, mas também como interagir com o programa concomitantemente (TA3),

6. O trabalho do tutor tem sido alvo de grande atenção. Este é considerado aquele que oferece assistência, proteção, ajuda, aquele que motiva, facilita e direciona o aluno no caminho a ser seguido, em outras palavras, suas ações são essenciais para promover a aprendizagem dos alunos. A familiaridade do tutor com o ambiente tecnológico é essencial, entretanto, há outras competências que o tutor tem que apresentar, entre elas a compreensão de processos interacionais é crucial. O tutor deve guiar o processo de aprendizagem dos alunos, deve identificar dificuldades, sugerir novas leituras e atividades e contribuir nas interações dos participantes. Desistências em cursos online podem advir de falhas nas interações com os estudantes, e a responsabilidade de manter o aluno participando do curso acaba sendo irremediavelmente atribuída aos tutores uma vez que suas principais tarefas são: diagnosticar as inclinações de aprendizagem dos participantes, monitorar seus progressos, observar suas dificuldades, estimular, desafiar e avaliar a qualidade de sua aprendizagem (TA2),

7. Cabe ao tutor estar atento às necessidades dos alunos atuando como ponte entre suas necessidades e as propostas do professor conteudista. Dessa forma, compreende-se que o tutor tem, de fato, um papel central na assistência/suporte ao referido professor. Assim, o trabalho do tutor deveria ocorrer não apenas durante a implementação do curso, mas também no processo 
de preparação do material. Dentre as qualidades que se espera de um tutor destacam-se: capacidade de aceitação, gentileza, honestidade, empatia e estar atento e pronto a ajudar. Dentre as funções de um tutor encontram-se: a de facilitador, a de gerenciamento e a função de técnico. Como facilitador da aprendizagem, o tutor instiga as discussões entre alunos, o entendimento do conteúdo e a troca de insights. No papel de gerenciador, o tutor organiza horários e agendas para estruturar a participação dos alunos. Como técnico, o tutor é visto como aquele que tem o conhecimento aprofundado da plataforma na qual o curso está inserido, sendo que este conhecimento o capacita a auxiliar/facilitar o acesso dos alunos por meio de instruções individuais e coletivas mais precisas (TA2),

8. A eficácia do ensino a distância, quando comparada aos contextos presenciais, tem sido objeto de estudo. Apesar das iniciativas de educação digital aumentarem as oportunidades de aprendizagem, o uso da tecnologia no ensino pode levar a sentimentos de alienação e isolamento que podem explicar os altos níveis de desistência quando comparados a cursos presenciais. Atividades utilizadas em ambiente presencial podem ser adaptadas e transferidas a ambientes virtuais resultando positivamente na aprendizagem dos alunos. De fato, professores e tutores podem utilizar metodologias e materiais presenciais como base do desenvolvimento de cursos online e, além disso, uma vez que tenham experiência em ensino à distância, eles tendem a adicionar componentes virtuais em seus contextos de ensino presencial. A tendência para o futuro do ensino universitário é combinar as aulas presenciais e as instruções mediadas por computador, o chamado blended learning (TA3), 
9. Há duas formas de interação que podem acontecer em um curso online: síncrona e assíncrona. Na primeira, os participantes da interação devem estar disponíveis online ao mesmo tempo para que a comunicação ocorra (como no caso dos chats, conferências web e mensagens instantâneas) e, na segunda, não há esta limitação de tempo e espaço, portanto, os participantes podem interagir sempre que a sua disponibilidade permitir, como no caso dos e-mails, fóruns online e blogs (TA4)

10. Multiletramento pode ser definido como um tipo de alfabetização que não está centrada apenas no desenvolvimento linguístico, mas que foca em diferentes modos de representação. Ao ler e compreender o mundo através do multiletramento, o aluno será capaz de entender e interpretar as informações que representam diferentes contextos e culturas. $\mathrm{O}$ uso de material multimodal tem por objetivo promover o uso de fontes autênticas e dinâmicas (vídeos, textos, anúncios) encontrados em muitos dispositivos eletrônicos. Todas essas novas formas de interação requerem uma nova forma de leitura, uma alfabetização multimodal, sendo que, para se sentir efetivamente como parte desse novo ambiente, deve-se ter o conhecimento para usar essas linguagens múltiplas. A partir de uma educação multimodal, professores e alunos passam a sentir-se como verdadeiros cidadãos, capazes de lidar com diferentes tipos de desafio (TA5)

11. A multimodalidade e a pedagogia dos multiletramentos buscam esclarecer o que os alunos precisam aprender e como os professores podem prover os melhores materiais e métodos para engajá-los nas atividades propostas (TA5) 
Observa-se que nesta etapa de revisão de literatura os estagiários assumiram como suas próprias as representações sobre educação e TIC. Isto se deu pela reprodução, em paráfrases, dos posicionamentos dos autores lidos. A apropriação sem questionamentos dessas representações sobre o cenário atual de educação e TIC na seção de revisão de literatura pode ser vista como uma etapa de acesso ao conhecimento, no qual o texto escrito assume autoridade indiscutível. A falta de experiência em contextos educacionais semelhantes aos que estavam vivenciando, além da própria compreensão do papel da revisão de literatura em artigo acadêmico podem ter sido responsáveis por essa aceitação. Observe-se também que o próprio desejo de realização de estágio nessa modalidade também sinalizava uma atitude positiva em relação ao uso de TIC no ensino. Após a realização das atividades é que posicionamentos mais críticos puderam ser elaborados, conforme veremos a seguir.

\section{Significações da prática nas conclusões finais dos 'papers'}

Além da revisão de literatura, na qual os professores em formação tomaram contato com as posições de outros autores, a partir da coleta de dados ${ }^{16}$ e sua análise, eles expuseram suas conclusões, apontando para questões que seguem:

1. Embora tenham vivenciado o uso de algumas ferramentas tecnológicas ao longo do curso (inclusive na plataforma Moodle), alguns dos participantes se sentiram inseguros e apontaram que não estavam preparados para ensinar em um curso online.(TA1) 
2. Paradoxalmente, os participantes reconheceram que a tecnologia evolui de modo mais rápido do que a capacidade de os professores se preparem antecipadamente para ela. (TA1)

3. O treinamento para a tutoria parece não fazer diferença sobre o desenvolvimento de concepções sobre um "bom tutor". Tanto tutores experientes quanto os participantes partilharam de crenças sobre quais requisitos são necessários para bom desempenho desse papel em curso online. (TA2)

4. Razões técnicas dificultaram o desempenho de tutoria dos professores em formação. (TA2)

5. Características pessoais parecem predominar na definição do que vem a ser um bom tutor em AVA. (TA2)

6. Atividades produzidas para AVA podem ser adaptadas para situações de ensino presencial em escolas públicas, de acordo com a percepção de professoras que fizeram o curso. (TA3)

7. As interações realizadas durante o curso são fundamentais para a aprendizagem e os tutores precisam interagir regularmente com os alunos. (TA4)

8. Os fóruns não foram adequadamente explorados como oportunidades de interação significativa. (TA4)

9. As atividades planejadas poderiam ter sido melhor elaboradas, pois seguiram um formato bastante simples. (TA5) 
122 Telma Gimenez and Samantha G. M. Ramos, Planejamento...

10. Seria necessário ampliar a diversidade de tarefas e contemplar múltiplas formas de linguagem. (TA5).

O engajamento prático com todas as etapas de um curso online propiciou aos estagiários a oportunidade de refletir sobre a experiência à luz dos autores lidos. O reconhecimento de que havia lacunas e que vários aspectos poderiam ser melhorados é indício de que a experiência foi importante para melhor compreensão dos fatores envolvidos na educação a distância com uso de TIC. Dentre eles citamos a necessidade de formação prática dos profissionais envolvidos, com reconhecimento de necessidade de atualização constante, o papel da tutoria que guarda semelhanças com o ensino presencial, a necessidade de exploração mais aprofundada das ferramentas com seu potencial para promover interações significativas, e o reconhecimento da diferenciação entre tarefas em ambiente virtual e em ambiente presencial, tomando como base perspectivas de multiletramentos. Quer nos parecer que são compreensões adequadas para se levar em conta em contextos de educação mediada por TIC e que representaram um avanço em relação à revisão de literatura.

\section{Considerações finais}

Os 5 trabalhos acadêmicos produzidos a respeito dessa experiência como parte do cumprimento do estágio curricular revelam que essa aprendizagem ocorreu, a partir das várias atividades com as quais tiveram que se engajar. Ao revisarem a literatura sobre aspectos específicos de TIC e educação, especialmente em contexto online, os professores em formação aceitaram, sem questionamento, as posições ideológicas que reforçam a necessidade de preparação profissional para lidar com as inovações trazidas por novas ferramentas 
tecnológicas. Assim, essa atividade serviu para fortalecer a proposta trazida pela supervisora, garantindo sua adesão, e permitiu o engajamento nas tarefas propostas.

Considerando as análises e conclusões dos 'papers', concluímos que o engajamento prático em todas as etapas de um curso online propiciou aos estagiários a oportunidade de refletir sobre a experiência à luz dos autores lidos. Em outras palavras, foi possível vislumbrar novos entendimentos por parte dos discentes a partir das experiências práticas vivenciadas na elaboração e na implementação do SHEL.

$\mathrm{O}$ reconhecimento de que havia lacunas e que vários aspectos na produção e implementação do SHEL poderiam ser melhorados é indício de que a experiência foi importante para melhor compreensão dos fatores envolvidos na educação a distância com uso de TIC.

A proposta inovadora de realização de estágio curricular em curso de extensão na modalidade a distância aqui relatada orienta-se por uma visão de formação inicial de professores de inglês pautada nos preceitos de aprendizagem colaborativa e reflexiva que têm norteado os estágios curriculares na universidade onde atuamos. Ao proporcionar aos estagiários a oportunidade de se engajarem com todas as etapas de organização e oferta de um curso online sobre um tema do qual pouco sabiam, gerou várias "affordances", ou potenciais de aprendizagem (Daniels, 2001), inclusive para a supervisora, que também não tinha experiência com esse tipo de oferta.

A partir da constatação de que diferentes campos de atuação se abrem na atualidade para professores de inglês, a partir das inovações tecnológicas que abrem caminhos para a educação a distância, iniciou-se então uma experiência de aprendizado coletivo. A Internet permitiu a integração de atividades presenciais e não presenciais na orientação de estágio, na produção de questionário de sondagem de interesses e no uso de plataformas para interação entre supervi- 
124 Telma Gimenez and Samantha G. M. Ramos, Planejamento...

sora e estagiários. Exclusivamente virtuais foram os contatos com os alunos participantes do curso de extensão ofertado, por e-mail ou via fórum na plataforma Moodle. Essa estratégia permitiu que os estagiários vivenciassem e construíssem entendimentos sobre os diferentes modos de interação e elaborassem comparações entre os diferentes meios de comunicação, conforme apresentado.

Muitos espaços de aprendizagem foram construídos e outros identificados como passíveis de aprendizagem, conforme apontados nos artigos analisados, como, por exemplo, a necessidade de maior complexidade das tarefas (muitas com forte influência do ensino presencial, sem explorar os recursos multimodais). Esses resultados parecem sugerir que a continuidade de oferta de estágio em curso de extensão online pode significar uma inovação necessária em nosso país, onde a educação a distância ganha cada dia mais espaço. Proporcionalmente, devem também ser aumentadas as oportunidades de engajamento com práticas formativas que contemplem múltiplas modalidades de linguagem (verbal, imagética, sonora, visual) e coloquem desafios de aprendizagem para futuros professores.

\section{Notas}

1. Uma versão anterior deste trabalho foi publicada nos Anais do IV Congresso Internacional de Professorado Principiante, realizado em Curitiba, PR, de 19 a 21 de fevereiro de 2014. Neste texto damos sequência à análise dos artigos acadêmicos produzidos pelos estagiários.

2. Na área de ensino-aprendizagem de inglês tem sido comum encontrar várias fontes nas quais é possível realizar estudos, em muitos casos, de forma gratuita. Exemplo disso é a plataforma do curso MyEnglish Online (www. myenglishonline.com.br), disponibilizada a milhares de estudantes universitários interessados em participar dos programas de internacionalização da ciência, especialmente o "Ciência sem Fronteiras".

3. Uma busca no Google Scholar em 28/10/2013 revelou 1.220 artigos desde 2009 - nenhum deles tratava especificamente do estágio no formato 
aqui descrito. Da mesma forma, consulta ao Banco de Teses da CAPES com os termos "estágio curricular online/on-line" não retornou nenhum resultado.

4. Estagiários, discentes, futuros professores e autores (de trabalhos acadêmicos) serão os termos utilizados neste artigo para nos referirmos aos 5 alunos do 4 . Ano do curso de Letras da UEL que realizaram seus Estágios Supervisionados em AVA no ano de 2013.

5. 36 horas.

6. 16 horas para, no mínimo, 8 encontros para orientação

7. 20 horas para redação (em língua inglesa)

8. 104 horas, sendo: 20 horas para conhecimento do campo de estágio (instalações, diretores, professores, funcionários, participação em reuniões), projeto político-pedagógico, observação de aulas nas turmas para as quais ministrará aulas, 34 horas para planejamento, 40 horas de atuação como professor regente em sala de aula, 10 horas em atendimento individual a alunos.

9. Concluiram o curso: 11 professores da rede pública de ensino e 3 alunos do curso de graduação em Letras da mesma instituição.

10. Considerando que o curso foi totalmente ministrado em inglês, alguns participantes do curso online tiveram dificuldade em realizar a leitura de textos, assistir e compreender os vídeos e postar naquela língua. Embora o nível de proficiência esperado tivesse sido informado durante a divulgação do curso, alguns participantes avaliaram equivocadamente seu próprio desempenho.

11. Digital technologies in initial English language teacher education: the teaching practicum in an online environment.

12. "The Good Tutor": Perceptions of Online Tutors Working With Moodle.

13. Distance education and its transferability to a face to face context.

14. Brazilian online course participants' views on virtual interaction.

15. Assessing a short online course on the history of the English language: reflections from a course designer and tutor. 
16. Os instrumentos de coleta de dados variaram entre grupos focais gravados e transcritos (TA1), questionários (TA2, TA3 e TA4) e uma lista de checagem de avaliação (TA5)

\section{Referências}

DANIELS, H. Vygotsky e a pedagogia. São Paulo: Edições Loyola, 2001.

EL KADRI, M.S. Revisitando a prática de ensino no curso de Língua e Literatura Inglesa da UEL por meio da pesquisa: percursos, contribuições e desafios. In: Lima, R.; Lugle, Carvalho, Czernisz (Orgs.) Os estágios nas licenciaturas da UEL. Londrina: EDUEL, 2014, p. 35-60.

EL KADRI, M.S.; GAMERO, R.; GIMENEZ, T. Material didático para educação tecnológica de professores de inglês: uma experiência no âmbito do Programa 'Novos Talentos'. Linguagem e Ensino 15 (1), 2012, p. 181-212.

GIMENEZ, T. Caminhos e descaminhos: a pesquisa na formação do professor de língua estrangeira. The Especialist 19 (2), 1998, p. 257-271.

GIMENEZ, T. Tornando-se professores de inglês: experiências de formação inicial em um curso de Letras. In: M.H. Vieira-Abrahão. (Org.). Prática de Ensino de língua estrangeira: experiências e reflexões. Campinas, SP: Pontes e Artelíngua, 2004, p. 171-187.

GIMENEZ, T.; GÓES MONTEIRO, M. C. (Orgs.). Formação de professores de línguas na América Latina e transformação social. Campinas: Pontes, 2011.

LEFFA, V. Nem tudo que balança cai: Objetos de aprendizagem no ensino de línguas. Polifonia 12 (2), 2006, p. 15-45.

MARCELO DE JESUS, D. Linguagem e reculturação de professores no ambiente digital. In: S.M. Barros, A. A Assis-Peterson (Orgs.). Formação crítica de professores de línguas: desejos e possibilidades. São Carlos: Pedro e João Editores, 2010, p. 275-294.

MATEUS, E.F.; El Kadri, M.S.; Silva, K.A. (Orgs.). Experiências de formação de professores de línguas e o PIBID: contornos, cores e matizes. Campinas: Pontes, 2013. 
PAIVA, V. L. O. A formação do professor para uso da tecnologia. In: SILVA, K. A.; DANIEL, F. G; S. KANEKO-MARQUES, M.; SALOMÃO, A. C. B. (Orgs.). A formação de professores de línguas: novos olhares - volume II. Campinas: Pontes, 2012, p. 209-230.

PAIVA, V. L. O. English Language teaching and learning in the age of technology. Disponívelem<www.veramenezes.com>. Acesso em: 23 abr. 2013.

PERRY,E. H.; PILATI, M.L. Online learning. New Directions for Teaching and Learning 128, 2011, p. 95-104.

RAMOS, R. C. G. Uma experiência de formação on-line de professores de inglês para fins específicos. In: K.A Silva; F.G Daniel; S.M KanekoMarques \& A.C.B. Salomão (orgs). A formação de professores de línguas: novos olhares - volume II. Campinas: Pontes, 2012, p. 231-260.

QUEIROZ, V.; MUSTARO, P. N. Roles and competencies of online teachers. The Internet TESL Journal 9 (7), July 2003. Disponível em <http://iteslj. org/Articles/Queiroz-OnlineTeachers.html>. Acesso em 28 out. 2013.

SOTO, U.; GREGOLIN, I.V.; ROZENFELD, C. A formação inicial de professores de línguas: ações virtuais colaborativas para a articulação teoria-prática-reflexão. K. A. Silva; F. G. Daniel; S. M. Kaneko-Marques \& A. C. B. Salomão (Orgs.)(2012). A formação de professores de línguas: novos olhares - volume II. Campinas: Pontes, 2012, p. 261-282.

TORRES, P. L.; SIQUEIRA, L. M. M. Educação virtual nas universidades: as contribuições da aprendizagem colaborativa. Revista Historia de la Educacion Latinoamericana 14 (19), 2012, p. 175-204.

ZEICHNER, K. (Org.). A formação reflexiva de professores: ideias e práticas. Lisboa: Educa, 1993. 


\section{Apêndice}

Resumos dos 'papers' produzidos pelos professores em formação

\section{TA1}

\section{Digital Technologies in Initial English Language Teacher Education: Teaching Practicum in Online Environment.}

Digital technologies have become part of the everyday life, occupying a central position in many fields, including the educational context. Due to its constant growth and innumerous possibilities, research is needed in order to develop proposals for successful incorporation in schools as well as in online environments. Although face to face learning with the use of digital technologies has received attention in recent years, there is a gap when it comes to the education of language teachers in online courses. This study addresses the challenges in the implementation of a practicum in an online course entirely planned and delivered by the student teachers using the Moodle platform. The goal was to identify the student teachers' perceptions of their education and the use of digital technology. A focus group with four students in a Letras course was conducted. The data was audio recorded, transcribed and categorized according to the emerging themes: opportunities through their undergraduate course to deal with technology, concepts of learning and technology in public schools, the experiences related to the online course. In conclusion, the pre-service teachers felt uncomfortable and unprepared to teach in an online course; also, they identified the need for more precise instructions. Despite of that, they recognize that the technology develops faster than the ability to be prepared. 


\section{TA2}

\section{“The good tutor": perceptions of online tutors working with Moodle}

With the internet, Computer Mediated Learning (CML) courses became commonplace (PAIVA, 2012). In this new kind of educational environment the three main roles are the teacher, the tutor, and the student. Given the importance of online courses in today's world, a great deal of attention is focused on the tutor's role. This study aims at understanding the tutor's opinions about their role. The participants are the tutors working at the Distance Learning Center (NEAD) of a public university and a group of fourth year student teachers in a Letras-course, who were invited to answer a questionnaire on the characteristics of good tutor and how close they felt they were in relation to them. Their responses were classified according to Berge's proposal (1995). Berge claims that tutors are likely to develop one of the specific roles in online courses: Facilitator, Managerial and Technical. However, another category needed to be added in this analysis: personal traits, as the respondents referred to qualities needed to perform this role. The analysis reveals that, besides the level of experience, both NEAD tutors and Letras-Inglês students shared a perspective of what a good tutor is.

\section{TA3}

\section{Distance education and its transferability to face to face contexts}

With the emergence of digital technologies in various spheres of life, the teaching and learning of foreign languages could not remain untouched by these developments. Face to face education has been complemented by online courses that have grown with great speed (PAIVA, 2012). Therefore, the education of foreign language 
teachers has followed these developments and incorporated those technologies in classrooms. In Letras courses this has been done through the teaching of digital genres and the use of those technology tools to complement face to face teaching- learning. However, it is rare to find reports on the preparation for the use of technology in online environments. Our experience in the teaching practice with a course on Moodle provided an opportunity to consider how those tasks designed for virtual learning could be incorporated into state school classrooms. In order to achieve this objective, state school teachers who participated in the course "A short history of the English language" answered a questionnaire about the "transferability" of some of those tasks (module 3) to their classrooms. The responses indicate that the teachers considered most of them applicable to their high school classes, although recognizing the difficulties related mainly to the internet availability and computer access in schools.

\section{TA4}

\section{Brazilian online course participants' views on virtual interaction}

This paper is situated in the research area of distance learning, more specifically in virtual environments, a growing field of research, as evidenced by the vast amount of recent papers on the area ((NUGENT, 2009; MASON, 2011; LAMBROPOULOS, 2012; HAMILTON; HARLAND, 2012; PAIVA, 2012, among others). In this article, I analyze the views of Brazilian students on the interaction, through online forums, in an online course about the history of the English language, taught and tutored by pre-service teachers of Letras Inglês from the State University of Londrina, Brazil, in 2013. The data, collected through questionnaires required for course completion, point to three perspectives: (i) interaction as a clarification tool for 
the content presented in the lessons and/or the required tasks in the course, (ii) interaction as a valuable tool for the social construction of knowledge, and, finally, (iii) interaction as a compulsory task. The analysis, as well as the discussion of the results, may contribute to further research on the online course research field, and also help in the development of courses in virtual enviroments.

\section{TA5}

\section{Assessing a short online course on the history of the English language: reflections from a course designer and tutor}

Digital technologies have reached an unprecedented level in education nowadays. This evolution has created a common need for specific educational skills, a new literacy for operating and dealing with these new technologies is required. According to Luke (2000), educators need to develop appropriate pedagogical material for these new electronic environments in order to make a positive interference on how to use efficiently the many multimedia resources available. In this paper I analyze the activities in an online course developed by the $4^{\text {th }}$ years students of Letras - English course, from Universidade Estadual de Londrina in 2013, delivered through the Moodle plataform, using a checklist developed by Wright (s.d.) that included several elements of the course such as general information, accessibility, organization/layout, language and content. 
